\title{
ФИЗИЧЕСКИЕ МЕТОДЫ ЛЕЧЕНИЯ ДИАБЕТИЧЕСКОЙ ПОЛИНЕЙРОПАТИИ
}

\author{
А.В.Мусаев, С.Г.Гусейнова, *С.С.Имамвердиева \\ НИИ медииинской реабилитаиии, Баку
}

Д иабетические полинейропатии (ДПН) являются одним из наиболее распространенных и тяжелых осложнений сахарного диабета (СД). Прогрессирующий характер клинического течения и неблагоприятный прогноз при ДПН объясняют особое внимание ученых и клиницистов к этому заболеванию $(1,2,3,8)$. ДПН являются причиной снижения трудоспособности, качества жизни больных, фактором риска развития синдрома "диабетической стопы", нередко приводящем к ампутации и инвалидизации больных $(4,8)$. В частности, по данным International Working Group on the Diabetic Foot (17), от 40 до 70\% всех ампутаций нижних конечностей связано с сахарным диабетом.

На современном этапе лечение больных ДПН базируется на трех основных направлениях, связанных с коррекцией основных патогенетических механизмов развития заболевания, устраненением основных симптомов ДПН, улучшением качества жизни больных и предупреждением прогрессирования и развития осложнений ДПН $(4,5,9)$. Подобный подход к лечению ДПН предполагает использование широкого арсенала лекарственных средств, применение которых нередко сопровождается побочными действиями и аллергическими реакциями, и служит одной из основных причин снижения КЖ больных ДПН. В связи с этим все более важное значение в комплексной терапии больных ДПН занимают физические методы лечения $(8,10,11)$.

Широкие возможности применения физических факторов при ДПН, связаны с их многофункциональным действием на различные структуры организма, сопровождающимся каскадом физико-химических, биологических реакций и клинических эффектов (7), проявляясь разнонапраленным действием на отдельные звенья патогенеза заболевания и устране-

*e-mail: dsevinj@mail.ru нием основных клинических симптомов ДПН. Исследования последних лет свидетельствуют о высокой эффективности различных видов физических факторов в лечении больных ДПН даже в случаях неэффективности стандартной фармакотерапии $(9,10,11)$.

Одним из эффективных и щадящих методов физиотерапии является низкочастотная магнитотерапия, терапевтическая эффективность которой определяется высокой магнитной проницаемостью биологических тканей, обеспечивающих глубокое проникновение этих полей. Индуцируемые при этом в тканях вихревые потоки низкой частоты способны активировать обменные и микроциркуляторные процессы, улучшают мембранную активность, ионный транспорт в клетках, что в совокупности усиливает метаболическое обеспечение нейронов, улучшает функции периферических нервов $(6,13)$.

Широко используемая в Азербайджане иловая грязь озера Масазыр является уникальным целебным фактором, представляющим собой природный комплекс, насыщенный минеральными солями и биологически активными органическими веществами. Богатый химический состав, совокупность теплового и механического воздействия лечебной грязи, способствует нормализации основных метаболических процессов в клетках и тканях организма, активации регионарного кровотока, стимуляции регенеративных и репаративных реакций, что обеспечивает высокую клиническую эффективность пелоидотерапии при заболеваниях периферической нервной системы (14).

Исходя из вышесказанного, целью настоящего исследования явилось изучение эффективности применения низкочастотного импульсного сложномодулированного электромагнитного поля (ИСМ ЭМП) и пелоидотерапии в лечении больных с различной степенью тяжести ДПН. 
Под наблюдением находилось 114 больных ДПН, с различной степенью тяжести заболевания. Наряду со стандартным неврологическим обследованием все больные проходили тестирование по клиническим шкалам ДПН. Основные жалобы при ДПН (боль, жжение, онемение, парестезии) оценивались по шкале TSS. Шкала NIS отражала объективные признаки ДПН (нарушения чувствительности, рефлексов и мышечной силы) $(12,15)$. Вибрационная чувствительность изучалась методом вибротестирования. С целью получения обобщенной оценки о состоянии больных ДПН, анализировали изменения их качества жизни по разработанной нами специализированной анкете, включающей вопросы, касающиеся клинических проявлений сахарного диабета, ДПН и отражающих ограничения больных в социальной, производственной и бытовой сферах. Влияние физических факторов на состояние периферического нейромоторного аппарата оценивалось электронейромиографическим (ЭНМГ) исследованием, которое включало определение скорости проведения импульсов (СПИ) по двигательным волокнам срединного, локтевого, большеберцового и малоберцового нервов и амплитуды максимального М-ответа в мышцах кистей и стоп.

В зависимости от применяемой методики лечения больные были разделены на 2 клинические группы. 1-я группа (59 больных) получала ИСМ ЭМП от аппарата "Малахит-05" на верхние и нижние конечности и соответствующие сегментарные зоны, при нтенсивности магнитной индукции 8мТл, несущей частоте 10 Гц и модулирующей-0,5 Гц, по 10-15 минут на каждое поле, на курс 10-12 процедур. Больные 2-й группы (45 больных) принимали грязевые аппликации из иловой сульфидной грязи озера Масазыр на верхние и нижние конечности и соответствующие сегментарные зоны, при температуре грязи 40-420 С, продолжительности процедуры 20-25 минут, ежедневно, на курс лечения 10-12 процедур. В лечебный комплекс в обеих группах были включены массаж и лечебная гимнастика. Лечение проводилось на фоне диеты и приема привычных доз сахароснижающих препаратов.
Клинические проявления ДПН характеризовались разнообразием симптомов, отражающих чувствительные, двигательные и вегетативно-трофические нарушения. В соответствии с классификацией Peter J. Dyck и Peter K.Thomas (1999), основанной на данных клинико-электронейрофизиологических исследований определяли следующие степени тяжести заболевания: N1b - у 20 больных, стадия $\mathrm{N} 2 \mathrm{a}$-у 74, стадия N2b - у 15 больных и стадия N3 - у 5 больных.

Результаты тестирования больных по шкале TSS показали, что среди жалоб, предусмотренных в данной шкале, у наблюдаемых больных ведущее место занимали боли (у 89\% больных), которые локализовались преимущественно в дистальных отделах нижних конечностей и по интенсивности и частоте превышали все остальные жалобы (табл.1). Характерные для больных ДПН нейропатические боли сочетались с чувствительными расстройствами в виде жжения (у $38,6 \%$ больных) в симметричных участках голеней и стоп, в единичных случаях отмечали явления аллодинии, обусловленные наличием анормальной эктопической активности, вследствие демиелинизации периферических нервов. Частое онемение в стопах и в кончиках пальцев рук отмечали у 88,6 \% больных. Парестезии, проявляющиеся чувством покалывания и "ползания мурашек" в ногах, наблюдали в 36,1\% случаях. Суммарный показатель жалоб больных по шкале TSS

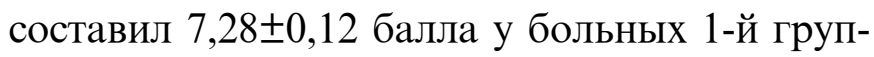

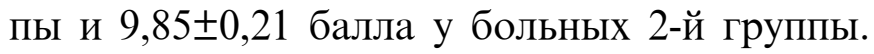
Помимо жалоб, предусмотренных в шкале TSS, больные нередко отмечали зябкость стоп (37,9\%), судороги в икроножных мышцах $(40,4 \%)$, дизестезии в виде ощущения "ватных" или "деревянных" ног (17,5\%).

Объективная оценка неврологических симптомов у больных ДПН свидетельствовала о том, что наиболее постоянным проявлением заболевания являются сенсорные нарушения различного характера и степени выраженности, выявляемые, как правило, по полиневритическому типу. Нарушение болевой чувствительности отмечалось у 93\% больных и составляло по шкале NIS $1,97 \pm 0,02$ баллов в 


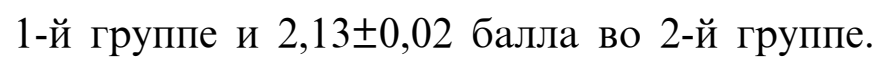
При этом гиперальгезия, обусловленная значительной сенситизацией ноцицептивных проводников, наблюдалась у 7,2\% больных. Снижение тактильной чувствительности отмечено у 35,5\% больных ДПН и составляло $1,78 \pm 0,04$ баллов и 1,92 $\pm 0,03$ балла соответственно. Расстройство мышечно-суставного чувства имело место в $21,7 \%$ случаях. Снижение порога вибрационной чувствительности (ВЧ), определяемое методом вибротестирования, выявлялось в 87,9\% случаях и нередко опережало другие клинические симптомы ДПН. Среднее количество баллов ВЧ по шкале NIS оказалось наиболее высоким в сравнении с другими видами чувствительности, составив 2,48 $\pm 0,02$ баллов в 1-й группе больных

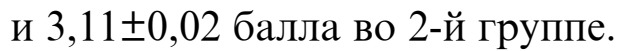

У 19,8\% больных ДПН были выявлены двигательные нарушения, при этом в большинстве случаев поражались мышцы дистальных отделов нижних конечностей. Снижение мышечной силы в сгибателях и разгибателях пальцев стоп наблюдалось у 18,1\% больных.
Снижение мышечной силы в проксимальных отделах нижних конечностей в сочетании с гипотрофией мышц по типу диабетической амиотрофии, было выявлено у 5 больных. Среднее количество баллов, характеризующих снижение мышечной силы у больных ДПН по

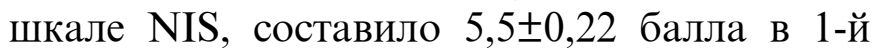
группе и 6,5 0,22 балла во 2-й группе. Изменения в рефлекторной сфере проявлялись снижением или выпадением сухожильных и периостальных рефлексов. Наиболее часто и выражено нарушались ахилловы рефлексы (у 80, $1 \%$ ), в меньшей степени коленные рефлексы (у $53,1 \%)$. Количество баллов по шкале NIS со стороны ахиллова рефлекса было максимальным (табл.1). Рефлексы с верхних конечностей страдали в меньшей степени. Суммарный показатель объективных симптомов по шкале NIS, составил 22,14 $\pm 0,12$ балла у больных 1-й

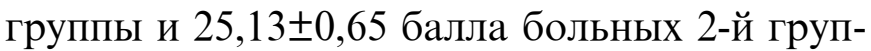
пы, при этом количество баллов нарастало в зависимости от степени тяжести ДПН и было максимальным в стадиях N2b и N3.

Изучение качества жизни больных с ДПН

Таблица 1. Динамика субъективных и объективных признаков ДПН по шкалам TSS и NIS (в баллах) (n=114)

\begin{tabular}{|c|c|c|c|c|}
\hline \multirow{2}{*}{ Шкалы } & \multicolumn{2}{|c|}{ 1-я группа $(\mathrm{n}=59)$} & \multicolumn{2}{|c|}{ 2-я группа (n=45) } \\
\hline & До лечения & После лечения & До лечения & После лечения \\
\hline \multicolumn{5}{|l|}{ Шкала TSS } \\
\hline Боль & $3,01 \pm 0,02$ & $1,78 \pm 0,05 * *$ & $3,75 \pm 0,03 * *$ & $1,85 \pm 0,05 * *$ \\
\hline Онемение & $2,78 \pm 0,04$ & $1,62 \pm 0,03 * *$ & $3,13 \pm 0,05^{* *}$ & $1,82 \pm 0,03 * *$ \\
\hline Жжение & $2,49 \pm 0,06$ & $1,51 \pm 0,15^{* *}$ & $2,67 \pm 0,02 * *$ & $1,79 \pm 0,04^{* *}$ \\
\hline Парестезии & $2,27 \pm 0,12$ & $1,44 \pm 0,1 * *$ & $2,78 \pm 0,03 * *$ & $1,53 \pm 0,05^{* *}$ \\
\hline Суммарный показатель & $7,28 \pm 0,12$ & $3,42 \pm 0,05^{* *}$ & $9,85 \pm 0,21 * *$ & $4,23 \pm 0,06 * *$ \\
\hline \multicolumn{5}{|l|}{ Шкала NIS } \\
\hline Мышечная сила & $5,5 \pm 0,22$ & $3,78 \pm 0,21 * *$ & $6,5 \pm 0,22$ & $4,21 \pm 0,21 * *$ \\
\hline Рефлексы: & & & & \\
\hline с двуглавой мышцы & $1,75 \pm 0,25$ & $1,75 \pm 0,18$ & $2,11 \pm 0,25$ & $2,11 \pm 0,18$ \\
\hline с трехглавой мышцы & $1,94 \pm 0,06$ & $1,94 \pm 0,05$ & $1,97 \pm 0,06$ & $1,97 \pm 0,06$ \\
\hline Карпорадиальный & $1,86 \pm 0,47$ & $1,86 \pm 0,52$ & $1,92 \pm 0,47$ & $1,92 \pm 0,47$ \\
\hline Коленный & $2,24 \pm 0,02$ & $2,24 \pm 0,01$ & $2,57 \pm 0,02$ & $2,57 \pm 0,01$ \\
\hline Ахиллов & $2,69 \pm 0,02$ & $2,69 \pm 0,01$ & $3,11 \pm 0,02$ & $3,11 \pm 0,04$ \\
\hline \multicolumn{5}{|l|}{ Чувствительность: } \\
\hline -болевая & $1,97 \pm 0,02$ & $1,84 \pm 0,05^{* *}$ & $2,13 \pm 0,02$ & $1,75 \pm 0,05 * *$ \\
\hline -тактильная & $1,78 \pm 0,04$ & $1,63 \pm 0,04 *$ & $1,92 \pm 0,03$ & $1,58 \pm 0,02 *$ \\
\hline -вибрационная & $2,48 \pm 0,02$ & $1,96 \pm 0,05 * *$ & $3,11 \pm 0,02$ & $2,12 \pm 0,05^{* *}$ \\
\hline -мышечно-суставная & $0,75 \pm 0,04$ & $0,64 \pm 0,02 *$ & $0,81 \pm 0,04$ & $0,56 \pm 0,02 *$ \\
\hline Суммарный показатель & $22,14 \pm 0,75$ & $20,07 \pm 0,52^{*}$ & $25,13 \pm 0,65$ & $22,07 \pm 0,63^{*}$ \\
\hline
\end{tabular}

Примечание: p - высчитан по отношению к исходному состоянию* - p<0,01; ** - p<0,001 
свидетельствовало о значительном влиянии клинических проявлений болезни на общее функционирование больных, что отражалось на настроении больных, вызывало у них апатию и чувство тревоги, ограничивало их бытовую и трудовую деятельность, нарушало полноценный отдых и суживало круг общения. Существенный дискомфорт вызывало также вынужденное ограничение в еде, а также необходимость постоянного наблюдения и лечения. Интегральный показатель качества жизни (ИКЖ), высчитанный путем суммирования по всем пунктам опросника, составил 32,8土1,2 балла в 1-й группе больных и $38,12 \pm 1,5$ балла во 2-й группе больных. Данный показатель достоверно нарастал в зависимости от тяжести ДПН и был максимальным у больных с тяжелой степенью ДПН (в

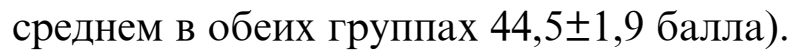

ЭНМГ исследованием в исходном состоянии было выявлено снижение скорости проведения импульса (СПИ) по двигательным волокнам всех обследованных нервов, что свидетельствовало о значительном нарушении проводящей функции нервов при ДПН, что повидимому, обусловлено нарушением местного метаболизма в нервной ткани, вследствие хронической гипергликемии, а также сопутствующим поражением сосудов, что приводит к нарушению энергообмена в нерве, его ишемизации и гипоксии (8).

Степень снижения СПИ коррелировала со стадиями ДПН и объективно характеризовала тяжесть поражения периферических нервов. Так, у больных в стадии N1b наблюдалось умеренное снижение СПИ по периферическим нервам верхних (на 12,5\% от нормы) и нижних конечностей (на 14,5\%) В стадии $\mathrm{N} 2 \mathrm{a}$ отмечалось более заметное уменьшение СПИ по периферическим нервам ниж-них конечностей (на 19,1\%). Значительное снижением СПИ по нервным волокнам (на 29\% в верхних и на 32\% в нижних конечностях) наблюдалось у больных в стадиях N2b и N3 заболевания с наличием выраженных чувствительных и двигательных нарушений.

Наряду со снижением СПИ у больных с ДПН наблюдалось уменьшение амплитуды М-ответа в мышцах кистей и стоп, указывающее также на поражение осевых цилиндров

Таблица 2.

Динамика ЭНМГ показателей у больных с ДПН под влиянием физических факторов

\begin{tabular}{|c|c|c|c|c|}
\hline \multirow[b]{2}{*}{ Показатели } & \multicolumn{2}{|c|}{ 1-я группа ( n=88) } & \multicolumn{2}{|c|}{ 2-я группа (n=38) } \\
\hline & СПИэфф, м/с & $\begin{array}{c}\text { Амплитуда } \\
\text { максимального } \\
\text { М-ответа, мВ }\end{array}$ & СПИэфф, м/с & $\begin{array}{c}\text { Амплитуда } \\
\text { максимального } \\
\text { М-ответа, мВ }\end{array}$ \\
\hline Срединный & $\begin{array}{l}49,8 \pm 1,5 \\
54,5 \quad 1,2 \\
* *\end{array}$ & $\begin{array}{l}\frac{5,1 \pm 0,3}{7,3} 0,0,6 \\
* * *\end{array}$ & $\begin{array}{l}41,8 \pm 1,3 \\
45,7 \\
*\end{array}$ & $\frac{4,3 \pm 0,3}{5,7 \quad 0,9}$ \\
\hline Локтевой & $\begin{array}{l}47,8 \pm 0,9 \\
51,6 \quad 1,2 \\
* * *\end{array}$ & $\begin{array}{ll}4,4 \pm 0,1 \\
6,1 & 0,2 \\
* * * & \end{array}$ & $\frac{49,1 \pm 1,2}{50,1 \quad 1,1}$ & $\frac{2,9 \pm 0,3}{3,1 \quad 0,1}$ \\
\hline Малоберцовый & $\begin{array}{l}40,5 \pm 0,4 \\
42,1 \quad 0,8 \\
*\end{array}$ & $\begin{array}{ll}2,3 \pm & 0,2 \\
3,6 & 0,1 \\
* * & \end{array}$ & $\frac{40,6+0,7}{41,4 \quad 0,8}$ & $\frac{3,1 \pm 0,7}{3,8 \quad 0,8}$ \\
\hline Большеберцовый & $\begin{array}{l}36,3 \pm 0,4 \\
39,7 \quad 0,6 \\
* * *\end{array}$ & $\begin{array}{ll}2,9 \pm & 0,3 \\
4,2 & 0,3 \\
* * & \end{array}$ & $\frac{38,1 \pm 0,8}{37,7 \quad 0,6}$ & $\begin{array}{ll}3,3 \pm 0,2 \\
4,3 & 0,3 \\
* * * & \end{array}$ \\
\hline $\begin{array}{l}\text { Контроль: } \\
\text { Срединный } \\
\text { Локтевой } \\
\text { Малоберцовый } \\
\text { Большеберцовый }\end{array}$ & $\begin{array}{l}58,6 \pm 1,8 \\
62,5 \pm 1,4 \\
54,8 \pm 1,4 \\
49,2 \pm 0,6\end{array}$ & $\begin{array}{l}6,73 \pm 0,4 \\
6,11 \pm 0,4 \\
2,3 \pm 0,21 \\
4,7 \pm 0,4\end{array}$ & & \\
\hline
\end{tabular}

Примечание: в числителе- показатели до лечения, в знаменателе- после лечения;

n- число обследованных нервов (показатели двух сторон объединены); р -высчитан по отношению к исходному состоянию; *-р 0,$05 ; * *$ р 0,$01 ; * * *$ - 0,001 . 
периферических нервов. Наибольшее снижение амплитуды максимального М-ответа наблюдалось в мышце отводящей I палец стопы, регистрируемой при стимуляции большеберцового нерва (табл.2). Изменение этого показателя также зависело от тяжести ДПН. Так, у больных в стадии N2a при стимуляции большеберцового нерва было выявлено снижение амплитуды мышечного потенциала на $50 \%$, а в стадиях N2b и N3 - на $87 \%$.

Выявленная зависимость нарушения проводимости нерва от клинической стадии заболевания обусловлена прогрессированием нейродистрофических процессов, нарушений кровообращения и микроциркуляции в пораженных тканях, приводящих к локальной гипоксии и усугубляющих имеющиеся расстройства проводящих функций нервных волокон. Выраженное снижение СПИ у больных в стадиях N2b и N3, повидимому, обусловлено демиелинизацией и вторичной аксональной дегенерацией периферических нервов.

Процедуры ИСМ ЭМП и пелоидотерапии хорошо переносились больными с различной степенью тяжести ДПН. Под влиянием применяемых физических факторов наблюдался заметный регресс основных клинических симптомов ДПН. В обеих группах больных наблюдалось выраженное уменьшение болей, онемения, жжения и парестезий, что выражалось в уменьшении количества баллов по шкале TSS ( $<<0,001)$ (табл.1). Интегральный показатель жалоб больных в конце магнитотерапии сни-

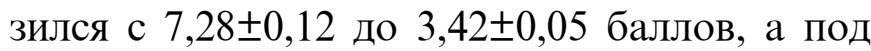
влиянием пелоидотерапии с 9,85 $\pm 0,21$ до 4,23 $\pm 0,06$ баллов. Изучение динамики суммарного показателя по шкале TSS в зависимости от тяжести ДПН показало, что уменьшение субъективных ощущений у больных произошло при всех стадиях заболевания ( $<<0,001)$.

В процессе лечения отмечались позитивные изменения и со стороны объективных неврологических симптомов, установленных у наблюдаемых больных. В обеих группах больных повысился исходно пониженный порог вибрационной чувствительности (p 0,001), что свидетельствовало об улучшении проводимости по толстым проводникам глубокой чув- ствительности, одна-ко процент улучшения был несколько выше у больных, получавших пелоидо-терапию (у 47\% больных). В 35,5\% случаях больных 1-й группы и у $36,7 \%$ больных 2-й группы произошло сужение зоны нарушений чувствительности. Нарастание мышечной силы было отмечено у $32 \%$ больных 1й группы и 25\% больных 2-й группы.

Вместе с тем, следует отметить, что положительная динамика объектив-ных клинических симптомов по шкале NIS в поздних стадиях ДПН была менее выраженной, что отражалось на результатах лечения больных. Наиболее высокий процент значительного улучшения и улучшения в обеих клинических группах больных был отмечен при начальных стадиях ДПН (у 76,6\% в 1-й группе и у 78,2\% во 2-й группе больных).

Применяемое лечение способствовало также улучшению показателей КЖ больных ДПН. На фоне регресса основных симптомов ДПН, отмечалось улучшение в эмоциональной сфере больных, нормализовался их сон. Наряду с этим, облегчилось перемещение больных, повысились возможности в их повседневной и трудовой деятельности, улучшилось проведение досуга. К концу курса лечения ИСМ ЭМП и пелоидотерапии интегральный показатель качества жизни достоверно снизился в обеих группах больных $(\mathrm{p}<0,001)$, что свидетельствует о восстановлении под влиянием физических факторов жизнедеятельности больных в целом, в сфере их физического, психологического и социального функционирования.

Оценка динамики ЭНМГ показателей свидетельствовала о благоприятном влиянии физических факторов на состояние периферического нейромотор-ного аппарата, что указывало на патогенетическую направленность применяе-мых физических факторов. Так, после курса лечения ИСМ ЭМП скорость проведения импульсов наросла по срединному нерву с $49,8 \pm 1,5$ до $54,5 \pm 1,2$ м/с, по локтевому с $47,8 \pm 0,9$ до $51,6 \pm 1,2 \mathrm{M} / \mathrm{c}$, по малоберцовому с

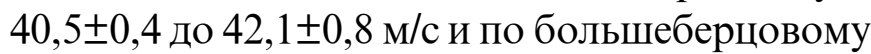
нерву с $36,3 \pm 0,4$ до $39,7 \pm 0,4 \mathrm{M} / \mathrm{c}$ (табл.2). Высокодостоверным оказалось увеличение СПИ по большеберцовому нерву $(\mathrm{p}<0,001)$. В основе 
улучшения проводящей функции периферических нервов под влиянием ИСМ ЭМП, повидимому, лежит нормализация проницаемости клеточных мембран, а также активация натрий-калиевого насоса в нервных клетках, являющимся основным субстратом проведения импульса по нерву. Влияние пелоидотерапии на проводящую функцию периферических нервов было менее выраженным (табл.2).

Под влиянием применения ИСМ ЭМП произошли положительные сдвиги и со стороны амплитуды максимального М-ответа (таблица 4.14). Это указывало на улучшение также мышечного звена нейромоторного аппарата в процессе магнитотерапии. К концу курса лечения амплитуда максимального Мответа наросла в мышце возвышения I пальца

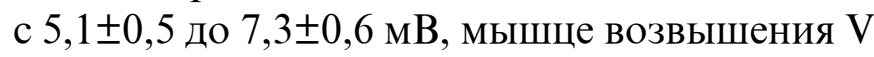

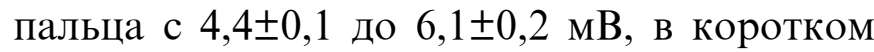
разгибателе пальцев стопы с 2,3 $\pm 0,1$ до $3,6 \pm 0,1$ мВ и в мышце, отводящей I палец сто-

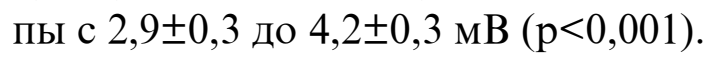

Под влиянием пелоидотерапии высокодостоверное повышение амплитуды максимального М-ответа было констатировано лишь в мышце, отводящей I палец стопы $(\mathrm{p}<0,001)$.

Таким образом, результаты проведенных клинических и электронейро-миографических исследований, показали, что применение ИСМ ЭМП и пелоидотерапии благоприятно влияет на клиническое течение ДПН, способствует регрессу основных субъективных и объ-

\section{СПИСОК ЛИТЕРАТУРЫ}

1.Балаболкин М. И., Чернышова Т. Е., Трусов В. В., Гурьева И. В. // Диабетическая нейропатия: патогенез, диагностика, классификация, прогностическое значение, лечение: учеб.-метод. пособие. - М.: Экспертиза, 2003.

2.Дедов И.И., Удовиченко О.В., Галстян Г.Р. // Диабетическая стопа. - М.: Практиче-ская медицина, 2005. C. $48-57$.

3.Друк И.В. Клиническое наблюдение сочетанных проявлений разных форм диабетической нейропатии: клинические проявления, подход к терапии нейропатической боли. Лечащий врач, 2013, с.43-53

4.Гордеев С.А., Турбина Л.Г., Зусьман А.А. Лечение болевой формы диабетической полиней-ропатии. Лечащий врач, 2011, с.12-15

5.Гурьева И.В., Комелягина Е.Ю., Кузина И.В. Диабетическая периферическая сенсомоторная нейропатия: ективных симптомов заболевания, улучшает функциональное состояние периферического нейромоторного аппарата и повышает качество жизни больных ДПН. Влияние ИСМ ЭМП при ДПН реализуется путем нормализации функционального состояния периферического-нейромоторного аппарата, а в основе терапевтического действия пелоидотерапии лежит преимущественное улучшение афферентных структур. Выявленные особенности в механизме действия ИСМ ЭМП и пелоидотерапии свидетельствуют о перспективности применения физических факторов в лечении больных ДПН, способствующих проявлению более выраженных клинических эффектов. Следует отметить, что длительные наблюдения за больными свидетельствуют о продолжительности сохранения достигнутых результатов, а также нередком регрессе стадий ДПН, что повышает неоспоримую роль применения физических факторов в профилактике развития грозных осложнений ДПН. Установленная зависимость эффективности проводимого лечения от тяжести ДПН указывает на необходимость проведения лечебных мероприятий на самых ранних стадиях развития заболевания.

На основании полученных данных можно заключить, что физические факторы отвечают всем основным требованиям терапии больных ДПН, что позволяет рекомендовать их для включения в алгоритм лечения данной категории больных.

метод. рекомендации. - М., 2000.

6.Зубкова С.М. Современные аспекты магнитотерапии. Физиотерапия бальнеология и реаби-литация 2004; 2: 3-10.

7. Илларионов В.Е. Теоретические аспекты физиотерапии Физиотерапия бальнеология и реабилитация 2008; 1: 3-10.

8 Котов С. В., Калинин А. П., Рудакова И. Г. // Диабетическая нейропатия. - М.: Медицина, 2000. - С. 45, 139, 150. 9. Мохорт Т.В., Ромейко Д.И. // Диабетическая полинейропатия: метод. руководство. - Минск, 2000.

10.Мусаев А.В., Гусейнова С.Г., Имамвердиева С.С. Применение импульсных сложномоду-лированных электромагнитных полей в лечении больных с диабетической полиневропатией. Журн. неврол. и психиатр, 2002, № 12, c. 17 - 24

11.Мусаев А.В., Имамвердиева С.С., Керимбейли У. К. 
Пелоидотерапия больных с диабети-ческой полинейропатией: клинико-иммунологическое исследование . Журн. неврол. и психиатр, 2008, № 2, с.17 - 24

12.Строков И.А., Новосадов М.В., Баринов А.Н., Яхно Н.Н. Клинические методы оценки тяжести диабетической полинейропатии. Неврологический журнал, 2000, № 5, c. 14-19

13.Улащик В.С. Теоретические и практические аспекты общей магнитотерапии. Вопр курортол физиотер и ЛФК 2001; 5: 3-8.
14.Эфендиева Ф.М. Лечебные грязи Азербайджанской CСР. Баку 1971; 181.

15.Brill V. NIS-LL: The primary measurement scale for clinical trial endpoints in diabetic peripheral neuropathy. EurNeurol 1999; 41: 501-503.

16.Dyck P.J., Thomas P. K, Diabetic Neuropathy 2-nd ed. Philadelphia: W.B. Saunders. 1999; 575.

17.Frykberg R. G, Armstrong D. G., Giurini J et al. Diabetic foot disorders: A Clinical Practice Guideline /. // J. of Foot \&Ankle Surgery. -2000. -Vol. 39 (5). -P. 2-49.

\title{
XÜLASə
}

\section{DİABETIK POLINEYROPATIYALARIN FİİKI ÜSULLARLA MÜALICCOSI}

\author{
Ә.V.Musayev, S.Q.Hüseynova, S.S.İmamverdiyeva \\ Elmi-Tadqiqat Tibbi Borpa Institutu, Bakl, Azərbaycan
}

Müxtəlif dərəcəli diabetik polineyropatiyası (DPN) olan 114 xəstədə alçaq tezlikli impulslu mürəkkəb modullaşdırılmış elektromaqnit sahələrinin (İMM EMS) və peloidoterapiyanın effektliliyi öyrənilmişdir. Aparılmış klinik və neyrofizioloji tədqiqatlar nəticəsində İMM EMS və peloidoterapiyanın DPN-ın əsas kliniki əlamətlərinin reqressinə, neyromotor apparatın funksional vəziyyətinin yaxşılaşmasına, həyat keyfiyyətinin yüksəlməsinə səbəb olması müəyyənləşdirilmişdir. Aydınlaşdırılmışdır ki, DPN xəstələrdə İMM EMS təsir mexanizminin əsasında periferik sinirlərin ötürücülük qabiliyyətinin yaxşılaşması, peloido-terapiyanın təsir mexanizminin əsasında isə afferent strukturların vəziyyətinin yaxşılaşması durur. Alınmış nəticələr fiziki faktorları DPN xəstələrin müalicə alqoritminə daxil etməyə imkan verir.

\section{SUMMARY}

\section{PHYSICAL METHODS FOR THE TREATMENT OF DIABETIC POLYNEUROPATHY}

\author{
A.V.Musayev. S.G.Huseynova, S.S.Imamverdiyeva \\ Research Institute of Medical Rehabilitation, Baku, Azerbaijan
}

The efficiency of use of low-frequency impulse complexly modulated electromagnetic field (ICM EMF), and pelotherapy in 114 patients with various severity degrees of diabetic polineyropathy (DPN) was studied. Based on the comlex clinical and electroneuromyographic study, showed that ICM EMF and peloidotherapy promote regression of the main clinical symptoms of DPN, improve functional status of neyromotor system, and the quality of life of the patients. It is, established that on the influence of ICM EMF mechanism the conducting functions of the peripheral nerves has improved. Also the therapeutic action of peloitherapy implements by the improvement of the afferent structure. The results allow including physical factors to the treatment of DPN patients. 